\title{
Dielectric Polarization Enhancement of Thermoplastic Elastomers for Sensing and Energy Harvesting Applications
}

\author{
Anup Poudel, Austin Coffey, James Kennedy, Sean Lyons, Ken Thomas, and Philip Walsh
}

\begin{abstract}
Nano-structured dielectric thermoplastic elastomers (DTEs) such as poly(styrene-co-ethylene-co-butylene-styrene) [SEBS] and poly(styrene-co-ethylene-co-butylene-styrene) -grafted- maleic anhydride[SEBS-g-MA] triblock co-polymers have been shown to have superior mechanical performances relative to conventional dielectric elastomers such as silicones because of their morphology; which comprises of continuous hard and soft block copolymers and physical cross-linking between same. However, historically their use in capacitive energy harvesting and sensing applications has been constrained by their relatively low dielectric permittivity. In this work, novel method for increasing the dielectric permittivity of DTE's while maintaining their mechanical performance by using electrically active modifiers was evaluated. Preliminary results showed a $110 \%$ and $99 \%$ increase in the dielectric permittivity, and a $787 \%$ and $300 \%$ increase in the storage modulus, of SEBS and SEBS-g-MA respectively upon addition of $10 \%$ carbon black. The storage modulus will be decreased if the materials are pre-strained. These results also indicate that relative changes in the electrical properties of polymer-additive composites is polymer-additive compatibility dependent (i.e. $1.20 \%$ decrease in the dielectric permittivity of SEBS and a $32.72 \%$ increase in the dielectric permittivity of SEBS-g-MA was observed upon addition of $10 \% \mathrm{BaTiO}_{3}$ ).
\end{abstract}

Index Terms-SEBS, SEBS-g-MA, dielectric permittivity, polarization.

\section{INTRODUCTION}

Dielectric thermoplastic elastomers are thermoplastic polymers which are rubbery in nature with thermoplastic processibility, and which demonstrates an electro-mechanical response when placed in an electric field. Thermoplastic copolymers may be styrene block copolymers, co-polyesters, thermoplastic polyurethanes and co-polyamides. Thermoplastic elastomers are formed by

Manuscript received May 13, 2015; revised October 13, 2015. This work was supported by Waterford Institute of Technology (WIT) Scholarship Award 2013.

Anup Poudel, Austin Coffey, and Philip Walsh are with the Convergent Technology Research Group (CTRG), Department of Engineering, Waterford Institute of Technology (WIT), Cork Road, Waterford, Ireland (e-mail: apoudel@wit.ie, acoffey@wit.ie, prwalsh@wit.ie).

Ken Thomas is with the School of Engineering, Waterford Institute of Technology (WIT), Cork Road, Waterford, Ireland (e-mail: kthomas@wit.ie).

James Kennedy is with the Centre for Materials Innovation and Design, Athlone Institute of Technology (AIT), Athlone, Ireland (e-mail: Jkennedy@ait.ie).

Sean Lyons is with the Applied Polymer Technologies, Athlone Institute of Technology (AIT), Athlone, Ireland (e-mail: slyons@ait.ie). blending rubber and thermoplastic polymers, where thermoplastic polymers and rubbers exist in different phases [1]. SEBS triblock is a type of styrene block copolymer which consists of polystyrene as end hard blocks and ethylene-butylene as mid soft blocks. Synthesis of SEBS triblock is done by the hydrogenation of double bonds present in poly (styrene- butadiene- styrene) [SBS] triblock. SEBS has become more and more attractive not only because it is stable and has high chemical, weather and heat resistance [2] but also due to its electroactive properties [3]; which have the potential for use in strain and stress sensing, actuation, and energy harvesting applications. Moreover, SEBS has been found to have higher elongation ( $47 \%$ versus $5 \%$ for shape memory alloys), greater energy density $(139 \mathrm{KJ} / \mathrm{m} 3$ versus $1 \mathrm{~J} / \mathrm{m} 3$ for shape memory alloys) and better electromechanical coupling efficiency ( 0.85 versus 0.5 for shape memory alloys) than other polymers like piezoelectric, shape memory alloys and magnetorestrictive materials used in similar applications [4]-[6]. Silicones and acrylics are the most commonly studied conventional dielectric elastomers. Both materials have very good response time $(>1 \mathrm{~ms})$ to electrical stimuli [7], good actuation pressure (0.1-100MPa), high strain (100\%) and low density (1/7ththat of piezoelectric materials). Conventional dielectrics, such as acrylics, are superior to conventional piezoelectrics as they exhibit high energy density (>3MJ/m-3), and are light weight [7], [8]. Even though such multilayer materials are able to mimic mammalian muscle with multi degrees of movement and have high dielectric permittivity, several problems such as material strength failure, dielectric failure, pull in failure, requirement of high biased voltage, creep, long relaxation time, high hysteresis loss and difficult processing etc. remain unresolved [6], [9]. Due to the ease of processing of thermoplastic elastomers like SEBS, mechanical and electrical performance enhancements can easily be achieved over conventional dielectric materials. These styrene based thermoplastic dielectric materials are therefore more suitable for energy harvesting applications and for deployment as sensors in structural health monitoring applications [6] due to their ability to tailor their dielectric capabilities with the addition of modifiers [10].

Sensors have already been made and tested using soft capacitors made up of conventional dielectric and thermoplastic materials (SEBS-g-MA) and have been found to be effective for monitoring the condition of civil infrastructure. Kollosche et al., [11] found that the accuracy of a sensing material increases with increasing capacitance or dielectric permittivity. 
This paper shows how conductive or high dielectric additives can be used for the modification of dielectric properties for polarization and to improve the compatibility of dielectric thermoplastic nano-structured materials such as SEBS. Furthermore it is demonstrated that the sensitivity of these materials can be increased using simple production processes such as hot melt extrusion in place of conventional solvent methods; which are faster and more cost effective.

\section{MATERIALS}

Poly (Styrene-ethylene/butylene-styrene) [i.e. SEBS triblock] (KRATON® G1652 H Polymer) with linear structure and 29-30\% styrene content was obtained from Kraton polymer research, Belgium. Highly conductive, porous (porous volume: $480-510 \mathrm{ml} / 100 \mathrm{gm}$ ) and micro-sized carbon black (Kitjenblack®EC 600-JD) was obtained from AkzoNobel Functional Chemicals B.V., UK and high dielectric material BaTiO3 (100 nm, 99.9\%) was obtained from IoLiTec Ionic Liquids Technologies GmbH, Germany.

\section{PREPARATION OF NANO-COMPOSITES}

Material blending was carried out in a co-rotating twin-screw extruder (extruder 1) with L/D ratio of 25:1. Samples of SEBS and SEBS-g-MA with different percentages of $\mathrm{BaTi}_{3}$ (1\%, 5\% and 10\%) and carbon black (1\%, $5 \%$ and $10 \%)$ were subsequently produced. Extrusion was carried out at a screw speed of $70 \mathrm{rev} / \mathrm{min}$, torque between 15 to $10 \mathrm{Nm}$, die pressure between 5-10 Psi and temperature profile as per Table I.

TABLE I: TEMPERATURE PROFILE OF SEBS AND SEBS-G-MA COMPOSITE

\begin{tabular}{ccccccc}
\multicolumn{7}{c}{ (EXTRUDER 1) } \\
\cline { 2 - 7 } Materials & 1 & 2 & 3 & 4 & 5 & Die \\
\hline $\begin{array}{c}\text { SEBS } \\
\text { Composites }\end{array}$ & 32 & 176 & 220 & 240 & 240 & 240 \\
$\begin{array}{c}\text { SEBS-g-MA } \\
\text { Composites }\end{array}$ & 30 & 160 & 190 & 200 & 200 & 200 \\
\hline \hline
\end{tabular}

The extruded material from extruder 1 was chopped into pieces and fed into a separate co-rotating twin-screw extrusion machine (extruder 2) of L/D of 25:1 with haul off technique using a gravimetric feeder. The extrudate was then passed through a roller system running at a constant speed of $0.5 \mathrm{rev} / \mathrm{min}$ in order to produce a constant thickness sheet. Processing was carried out with a screw speed of $70 \mathrm{rev} / \mathrm{min}$, torque between 25 to $140 \mathrm{Nm}$, die pressure between 4-7 Psi and temperature profile listed as per Table II.

TABLE II: TEMPERATURE PROFILE FOR SEBS AND SEBS-G-MA COMPOSITE (EXTRUDER 2)

\begin{tabular}{cccccccc}
\hline \multicolumn{7}{c}{ Temperature } & Profile ( Zones) $\left({ }^{\circ} \mathrm{C}\right)$ \\
\cline { 2 - 7 } Materials & 1 & 2 & 3 & 4 & 5 & 6 & Die \\
\hline $\begin{array}{c}\text { SEBS } \\
\text { Composites }\end{array}$ & 30 & 100 & 180 & 220 & 240 & 245 & 245 \\
$\begin{array}{c}\text { SEBS-g-MA } \\
\text { Composites }\end{array}$ & 140 & 155 & 170 & 180 & 180 & 190 & 200 \\
\hline \hline
\end{tabular}

\section{Dielectric AND MEChanical Characterization}

Dielectric characterization of flat samples of thickness1-2 mm was carried out using a Solatrtron 1260 impedance analyzer with a 1296 dielectric interface. The 1296A dielectric interface is a fast, accurate and repeatable impedance measurement technique which gives information about the electrical characteristics for a wide range of materials including plastics, ceramics, ion conductors, dielectric, piezo/ferroelectrics and other materials with an impedance range of more than $1014 \mathrm{~T}_{\Omega}$ across a frequency range of $10 \mu \mathrm{Hz}$ to $10 \mathrm{MHz}$. In addition, a Solatron $12962 \mathrm{~A}$ sample holder was used to facilitate measurement of the solid samples; which consisted of two parallel electrodes, both of $40 \mathrm{~mm}$ diameter, between which the material was placed and a 5Vrms alternating voltage applied. Finally, the storage moduli of the extruded samples were measured using a TA Instruments DMA 800 (dynamic mechanical analyzer) at $31^{\circ} \mathrm{C}$ at a frequency of $1 \mathrm{~Hz}$.

\section{RESUlTS AND DisCUSSION}

The dielectric permittivity calculated for SEBS and SEBS-g-MA composites from the Solartron 1296 at a frequency of $1 \mathrm{KHz}$ is shown Table III. These results have not been computed using a correction factor.

TABLE III: DIELECTRIC CONSTANT OF NANO-COMPOSITE OF DTES WITH CARBON BLACK (CB) AND BATIO ABT $_{3}$ WITHOUT CORRECTION FACTOR Dielectric constant of nano-composite at $1 \mathrm{KHz}$ $\left(\varepsilon_{\mathrm{r}}\right)$ directly from instrument without correction

\begin{tabular}{ccc} 
Additives & \multicolumn{2}{c}{ factor } \\
\cline { 2 - 3 } & $\mathrm{s}$ SEBS & SEBS-g-MA \\
\cline { 2 - 3 } & $(10-2)$ & $\varepsilon \mathrm{r}(10-2)$ \\
\hline Pure & 3.76 & 4.62 \\
CB -1\% & 3.93 & 5.49 \\
CB-5\% & 5.64 & 5.95 \\
CB -10\% & 7.94 & 9.22 \\
BT-1\% & 7.94 & 4.62 \\
BT-5\% & 3.76 & 4.68 \\
BT-10\% & 3.15 & 5.03 \\
\hline \hline
\end{tabular}

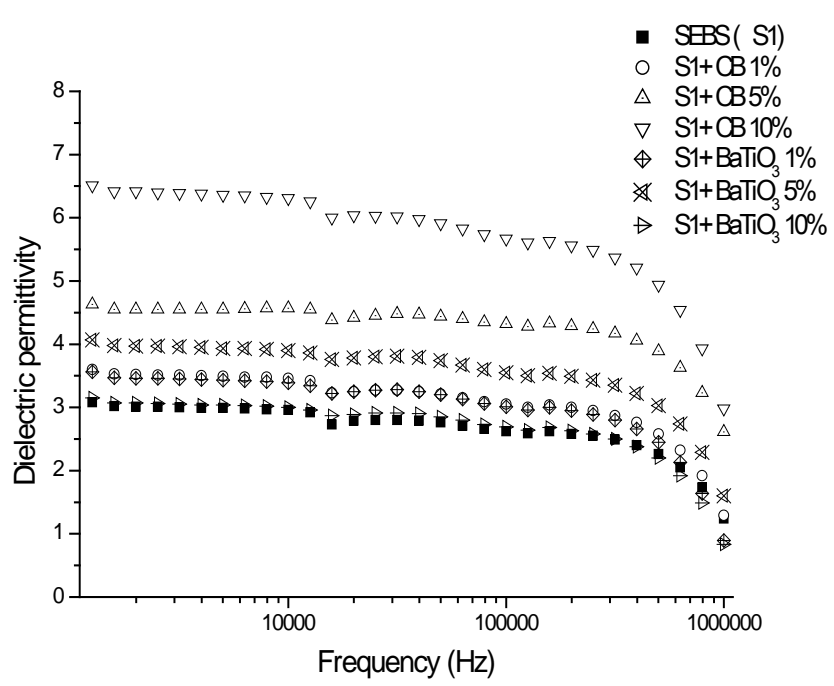

Fig. 1. Dielectric permittivity of SEBS composite with different percentage of carbon black and $\mathrm{BaTiO}_{3}$.

The dielectric permittivity obtained from nano-polymer composites was systematically smaller by a factor of 
approximately 100 compared to that reported in the literature [2], [12]. A correction factor was therefore applied by measuring the permittivity of the air at a distance of $1.5 \mathrm{~mm}$ between two electrodes which is believed to have an absolute value of 1 from $1 \mathrm{~Hz}$ to $1 \mathrm{MHz}$. The correction factor calculation for $1 \mathrm{KHz}$ was calculated to be 72 . This correction factor is used to calculate a reference of permittivity of air which is further modified from 72 to 82 for curve smoothing.

The relative dielectric permittivity of SEBS and SEBS-g-MA with carbon black and $\mathrm{BaTiO}_{3}$ at a test frequency of $1 \mathrm{KHz}$, after application of the correction factors discussed, are shown in Table IV. Similarly the final graphs for the dielectric permittivity of SEBS and SEBS-g-MA composites are shown in Fig. 1and Fig. 2 respectively.

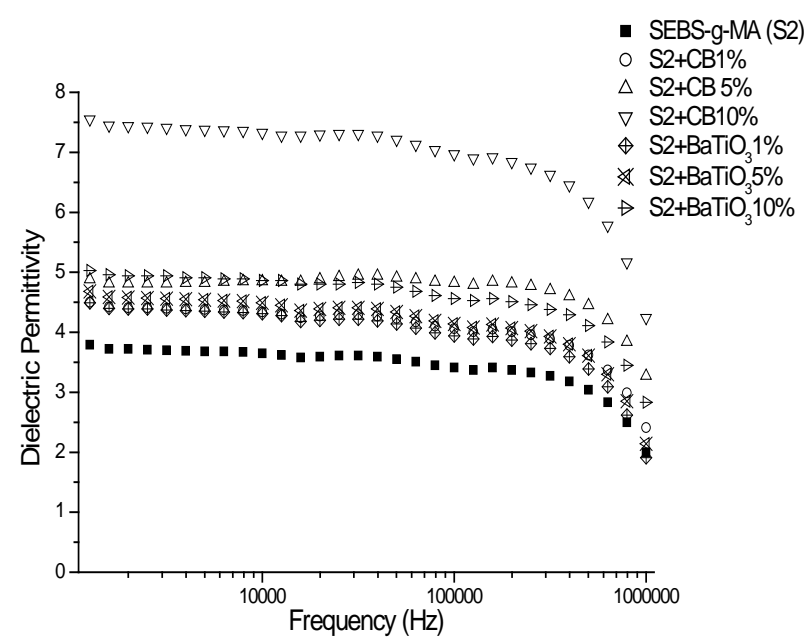

Fig. 2. Dielectric permittivity of SEBS-g-MA with different percentage of carbon black and $\mathrm{BaTiO}_{3}$.

The graphs for SEBS-carbon black and SEBS-g-MA-carbon black composites are comparable to the work of Stoyanov (2010). However, the relative change in permittivity from addition of carbon black is found to be different than in Stoyanov's work. Stoynov found the dielectric permittivity of SEBS to be 27 at $100 \mathrm{~Hz}$ upon addition of $4 \%$ of carbon black, whereas, the dielectric permittivity of SEBS was found to be only 7.5 at $100 \mathrm{~Hz}$ upon addition of $10 \%$ carbon black in this work. This may be because the method of composite preparation in this work (hot melt extrusion) is different than production techniques used by Stoyanov (solvent casting method). In addition to this, the dielectric measuring techniques used, and thickness of samples in this work also differ from the techniques used by Stoyanov. Like Stoyanov's work, the dielectric permittivity does not change so much with frequency at low concentration of carbon black in SEBS. This result holds true for SEBS-g-MA with carbon black as shown in Fig. 2 above and Table IV below.

Table $\mathrm{V}$ shows the change in dielectric permittivity and storage modulus for nano-composites transverse and parallel to extrusion (i.e. the axis of screw rotation) with the addition of nano- inorganic modifiers at a test frequency of $1 \mathrm{~Hz}$. In addition to the changes in electrical properties from the electric modifiers used, there is also a change in storage modulus for all materials. The stiffness of the composite materials were enhanced in the traverse direction making them less sensitive to low pressure strain sensing and energy harvesting applications. However, this effect will be reduced by swelling the materials in paraffin oil or by pre-straining as predicted by Mullin's effects. Rubbery materials tend to have higher stiffness in the first cycle of stretching, which tends to decrease in the second cycle. Even though the Mullin's effect will be reduced by pre-staining or swelling the polymers in a solvent(s), the addition of electric fillers will cause some increase in stiffness. Addition of carbon black to SEBS and SEBS-g-MA increases the dielectric permittivity by $130 \%$ and $113 \%$ respectively; as well as increasing the storage moduli of the materials by $787 \%$ and $300 \%$ respectively. However, the increase in stiffness in the transverse direction is very high in comparison to the dielectric permittivity increase(s) observed. In the case of SEBS-g-MA, the dielectric permittivity increase (35.65\%) achieved with the addition of $10 \% \mathrm{BaTiO}_{3}$ is greater than the storage modulus increase (10\%) observed. In contrast, the dielectric permittivity of SEBS is seen to decrease by $7.38 \%$ upon addition of $10 \% \mathrm{BaTiO}_{3}$; while the mechanical stiffness is seen to increase by $13.71 \%$.

TABLE IV: CORRECTED DIELECTRIC PERMITTIVITY OF SEBS AND SEBS-G-MA WITH CARBON BLACK (CB) AND BATIO 3 (BT) USING CORRECTION FACTOR

\begin{tabular}{|c|c|c|}
\hline \multirow{3}{*}{ Additives } & \multicolumn{2}{|c|}{$\begin{array}{l}\text { Dielectric constant of nano- composite at } 1 \mathrm{KHz}(\varepsilon r) \\
\text { with percentage changed with additives }\end{array}$} \\
\hline & SEBS & SEBS-g-MA \\
\hline & er (\% change) & er $(\%$ change $)$ \\
\hline Pure & 3.18 & 3.79 \\
\hline CB-1\% & 3.72 (16.9) & 4.5 (18.7) \\
\hline CB-5\% & $4.77(50)$ & 4.85 (28) \\
\hline CB $-10 \%$ & $6.71(111)$ & 7.56 (99) \\
\hline BT-1\% & 3.56 (11.69) & 4.49 (18.6) \\
\hline BT $-5 \%$ & 4.07 (27.68) & 4.68 (19.6) \\
\hline BT-10\% & $3.15(-1.2)$ & $5.03(32.8)$ \\
\hline
\end{tabular}

TABLE V: DiELECTRIC PERMITTIVITY AND STORAgE MODULUS OF NANO-COMPOSITES MEASURED AT A TEST FREQUENCY OF $1 \mathrm{~Hz}$

\begin{tabular}{|c|c|c|c|c|c|c|}
\hline \multirow{3}{*}{$\begin{array}{l}\text { Addi } \\
\text { tives }\end{array}$} & \multicolumn{2}{|c|}{$\begin{array}{l}\text { Dielectric constant } \\
\text { of nano- composite } \\
\text { at } 1 \mathrm{~Hz}(\varepsilon r)\end{array}$} & \multicolumn{2}{|c|}{$\begin{array}{l}\text { Storage modulus } \\
\text { at } 1 \mathrm{~Hz} \text { and } 31{ }^{\circ} \mathrm{C} \\
\text { in transverse } \\
\text { direction to } \\
\text { extrusion }\end{array}$} & \multicolumn{2}{|c|}{$\begin{array}{c}\text { Storage modulus at } \\
1 \mathrm{~Hz} \text { and } 31{ }^{\circ} \mathrm{C} \text { in } \\
\text { transverse } \\
\text { direction to } \\
\text { extrusion }\end{array}$} \\
\hline & SEBS & $\begin{array}{c}\text { SEBS-g- } \\
\text { MA }\end{array}$ & SEBS & $\begin{array}{l}\text { SEBS- } \\
\text { g-MA }\end{array}$ & SEBS & $\begin{array}{c}\text { SEBS-g } \\
\text {-MA }\end{array}$ \\
\hline & $\begin{array}{c}\varepsilon \mathrm{r} \\
(\% \Delta)\end{array}$ & $\begin{array}{c}\varepsilon r \\
(\% \Delta) \\
\end{array}$ & $\begin{array}{l}\mathrm{MPa} \\
(\% \Delta)\end{array}$ & $\begin{array}{l}\mathrm{MPa} \\
(\% \Delta)\end{array}$ & $\begin{array}{l}\mathrm{MPa} \\
(\% \Delta)\end{array}$ & $\begin{array}{l}\mathrm{MPa} \\
(\% \Delta)\end{array}$ \\
\hline Pure & 2.98 & 3.73 & 5.16 & 4.126 & 104.27 & 70.70 \\
\hline $\begin{array}{l}\text { BT- } \\
10 \%\end{array}$ & $\begin{array}{c}2.76 \\
(-7.38)\end{array}$ & $\begin{array}{c}5.06 \\
(35.65)\end{array}$ & $\begin{array}{c}5.84 \\
(13.17)\end{array}$ & $\begin{array}{l}4.57 \\
(10)\end{array}$ & $\begin{array}{l}75.65 \\
(-27.5)\end{array}$ & $\begin{array}{c}44.05 \\
(-37.7)\end{array}$ \\
\hline $\begin{array}{l}\text { CB- } \\
10 \%\end{array}$ & $\begin{array}{l}6.86 \\
(130)\end{array}$ & $\begin{array}{c}7.97 \\
(113.67)\end{array}$ & $\begin{array}{l}45.79 \\
(787)\end{array}$ & $\begin{array}{l}17.76 \\
(300)\end{array}$ & $(-11.8)$ & (8.84) \\
\hline
\end{tabular}

Unlike the high increases in storage modulus observed in the transverse direction, both modifiers (Carbon black and $\mathrm{BaTiO}_{3}$ ) decrease the storage modulus of the nano-composites; except in the case of SEBS-g-MA-carbon black nano-composites where addition of $10 \%$ carbon black is shown to increase the storage modulus by $8.84 \%$, as 
shown in Table V. The decrease in mechanical stiffness observed is due to the presence of low shear stress along the axis of screw rotation during extrusion.

Due to the anisotropic nature of these thin films manufactured using extrusion, thin film sensors fabricated by this process tend to sense compression forces with higher relative deformation in the transverse direction than in the longitudinal direction. This is verified in that the storage modulus in the transverse direction is very low compared to that for the longitudinal direction in low deformation applications. Hence, addition of electric modifiers tends to decrease the sensitivity if no increase in dielectric permittivity is obtained; although a decrease in storage modulus along the screw-rotation axis somehow improves the sensitivity of stress and strain thin film sensors produced by extrusion.

A small increase in storage modulus (13.71\%) in the transverse direction and a large decrease in storage modulus along the screw-axis $(-37.7 \%)$ together with a significant increase in the permittivity (35.67\%) makes SEBS-g-MA with $10 \% \mathrm{BaTiO}_{3}$ very suitable for stress and strain sensors and energy harvesting application for a range of mechanical stimuli.

As is self-evident, carbon black tends to improve the dielectric permittivity of the polymer matrix to some threshold as predicted by percolation theory [13], but when the threshold value is reached, it tends to make the polymer matrix conductive. Moreover, this threshold is dependent on the electrical properties of carbon black; which in-turn is contingent on the shape, orientation and dispersion of same [14]. Apart from conduction path theory (percolation theory), the electrical conductivity of carbon filled polymers has also been described using electron tunneling theory and electric field radiation theory [15]. Percolation theory defines that conduction occurs between carbon aggregations due to electron transfer mechanisms making the polymer matrix conductive [16]. Electron tunneling theory [17] and electric field radiation best describes the conduction mechanisms below the percolation threshold [18]. When the carbon black fillers are below the threshold, carbon aggregations are isolated from each other making the composite highly resistive, similar to pure polymers [19]. The increase in dielectric permittivity in carbon filled composites occurs below this threshold value, mainly because of interfacial polarization (polarization between the polymer matrix and carbon particles) and charge mobility. The interfacial polarization is the result of the assembly of different charges at the polymer-additive interface, resulting in a high dielectric constant [20]-[22].

Fig. 1 and Fig. 2 show that the relative permittivity of nano-composite decreases with increasing frequency for all concentrations of carbon black. This result compares favorably with the work of Stoyanov [2]. The type of carbon black also affects the conductivity of the material and hence the interfacial polarization and charge mobility resulting in different dielectric constants for different filler concentrations. As in non-polarizing SEBS, the addition of conductive additives like carbon black in a polarizing material like SEBS-g-MA also increases the dielectric permittivity in a similar fashion.
As the literature suggests [23], the addition of high dielectric materials like $\mathrm{BaTiO}_{3}$ tend to increase the dielectric permittivity of the nano-polymer composite. In Fig. 1 and Table IV, it is clearly observed that the increase in dielectric permittivity of SEBS with highly polar dielectric fillers content like $\mathrm{BaTiO}_{3}$ occurs up to a certain percentage (typ. $5 \%$ ). Even though the permittivity of SEBS with high percentages is expected to increase with increased amounts of $\mathrm{BaTiO}_{3}$, the permittivity of the materials at high percentages of $\mathrm{BaTiO}_{3}$ (10\%) show a decrease in relative dielectric permittivity. This decrease in the dielectric permittivity of the polymer for increased dielectric filler content is very peculiar as it directly ignores the concept that relative permittivity should increase with higher concentrations of dielectric fillers as a result of the influence of particle distribution, polarization and interfacial polarization between the filler and polymer matrix. This type of effect is also found by Patsidis et al [24]. Furthermore, the decrease in permittivity with increased filler content in different epoxy composites is also reported in the literature [25]. This result is not seen in Stoyanov work with SEBS [2] where compatibility between materials was improved. Hence, attaching a polar molecule like MA to SEBS provides higher mixing compatibility of BaTiO3 to SEBS as shown in Fig. 2 and Table IV thereby increasing the dielectric permittivity. It can't be directly suggested that polar materials with polar fillers are compatible as compatibility differs with the interaction between polymer molecules after adding fillers into the polymers, interaction between fillers and polymer molecules and finally, interaction between filler and filler particles. However, by attaching polarizing molecules MA to SEBS (.i.e. forming SEBS-g-MA), enhancement of compatibility has led to an increase in the relative permittivity at higher percentages of dielectric fillers.

The impregnation of $10 \%$ silicone oil coated $\mathrm{TiO}_{2}$ (polarizing dielectric material similar to $\mathrm{BaTiO}_{3}$ ), in SEBS, tends to increase the dielectric permittivity from 2.3 to 4 at $100 \mathrm{~Hz}$ as suggested by Stoyanov [2]. Yang and Kofinas [12] did similar experiments, but found the dielectric permittivity increased with an increase in $\mathrm{TiO}_{2}$ content ,but the mixing was done with polar SEBS by sulfonication.

Enhancement of the dielectric properties with $10 \% \mathrm{BaTiO}_{3}$ modifiers shows a higher compatibility to polarizing polymers like SEBS-g-MA than non-polarizing materials like SEBS. Bai et al. [26] suggested that the increase in dielectric permittivity is linearly dependent on the ceramic size particle. The dielectric permittivity of polarizing epoxy was increased to an absolute value 30-40 depending on $\mathrm{BaTiO}_{3}$ particle size at a ceramic loading of 40 vol\%. Moreover, according to Zhang et al. [23], nano-polymer composites show variation in dielectric permittivity for varied processing parameters like temperature. In addition to this, Kuo et al. [27] found that the relative change in the dielectric constant of polymer composites with $\mathrm{BaTiO}_{3}$ differs with heat treatment during milling and blend formation processes. These findings in literature suggest that processing temperature, screw speed, torque and feed volume also tend to change the dielectric permittivity constant of nano-polymer composites. 


\section{CONCLUSION}

A significant polarization enhancement was achieved on both non-polarizing (SEBS) and polarizing (SEBS-g-MA) copolymers using different concentrations of dielectric fillers/modifiers $\left(\mathrm{BaTiO}_{3}\right)$ and conductive filler materials (carbon black) processed via co-rotating, twin screw extrusion.

The dielectric permittivity of both SEBS and SEBS-g-MA were enhanced by ca. $100 \%$ upon addition of $10 \%$ carbon black (up to a threshold); as predicated by percolation theory. However, the stiffness of SEBS and SEBS-g-MA also increased by $787 \%$ and $330 \%$ respectively. This can be reduced by pre-straining or swelling the materials in a solvent(s); as predicted in the literature. A highly polarising modifier, $\mathrm{BaTiO}_{3}$, can also be used as a polarising enhancer in DTEs for energy harvesting and sensing applications. However, its chemical compatibility with DTEs is a major issue; as evidenced by the $1.20 \%$ decrease in the dielectric permittivity of SEBS upon addition of $10 \% \mathrm{BaTiO}_{3}$. Improved polymer-modifier/filler compatibility can be achieved with the addition of polarising groups in copolymers; as evidenced by the $18.6 \%, 19.6 \%$ and $32.8 \%$ increase in the dielectric permittivity of SEBS-g-MA upon addition of $1 \%, 5 \%$, and $10 \%$ of $\mathrm{BaTiO}_{3}$ respectively. Here MA acts as a polarising molecule. It is suggested that conductive fillers are superior to fillers/modifiers comprising a high dielectric constant (ignoring dielectric strength conditions and stiffness) for dielectric enhancement of DTEs; as conductive fillers tend to increase the dielectric permittivity of SEBS-g-MA by $99 \%$ whereas $\mathrm{BaTiO}_{3}$ modifiers only provide a $32.8 \%$ increase in the dielectric permittivity of same

These materials need to have high elastic compliance for sensing and energy harvesting applications; which can be achieved by swelling the polymers in a solvent like paraffin oil before extrusion to increase the material's elastic compliance. This remains a subject for future study.

In summation, realising (i) a 13.17\% increase and a 37.7\% decrease in the storage modulus for extruded SEBS-g-MA with $10 \% \mathrm{BaTiO}_{3}$ (i.e. transverse and parallel to the axis of extrusion respectively) and (ii) a significant increase (35.65\%) in the dielectric permittivity of same represents a fruitful accomplishment in attempting to increase the sensitivity of these materials towards sensing and energy harvesting applications.

\section{ACKNOWLEDGMENT}

The authors would like to thank Mr. Shane McGrath, Dr. Kieran O’Mahoney and Mr. Brian Coffey from the CTRG at WIT and the Applied Polymer Technologies Research Group, Athlone Institute of Technology.

\section{REFERENCES}

[1] K. E. Kear, "Structure of thermoplastic elastomers," Developments in Thermoplastic Elastomers, Smithers Rapra Press, 2003, vol. 10, pp. 3-6.

[2] H. Stoyanov, "Soft nanocomposites with enhanced electromechanical response for dielectric elastomer actuators," Doctor of Natural Sciences Doctoral Thesis, Faculty of Mathematics and Natural Sciences, University of Potsdam, Patsdam, 2011.
[3] R. Shankar, T. K. Ghosh, and R. J. Spontak, "Electroactive nanostructured polymers as tunable actuators," Adv. Mater., vol. 19, pp. 2218-2223, 2007.

[4] Z. Houqlng, L. Jianguo, W. Xmrong, X. Yanhong, and Z. Hongping, "Applications of Terfenol-D in China," Journal of Alloys and Compounds, vol. 258, pp. 49-52, 1997.

[5] A.-G. Olabi and A. Grunwald, "Design and application of magnetostrictive materials," Materials \& Design, vol. 29, pp. 469-483, 2008.

[6] C. M. Koo. (2012). Electroactive thermoplastic dielectric elastomers as a new generation polymer actuators. INTECH Open Access Publisher. [Online]. $\quad$ pp. $399-416 . \quad$ Available: http://cdn.intechopen.com/pdfs-wm/34076.pdf

[7] R. Pelrine, R. Kornbluh, Q. Pei, and J. Joseph, "High-speed electrically actuated elastomers with strain greater than 100\%," Science, vol. 287, pp. 836-839, 2000.

[8] R. Shankar, T. K. Ghosh, and R. J. Spontak, "Electromechanical response of nanostructured polymer systems with no mechanical pre-strain," Macromolecular Rapid Communication, vol. 28, pp. 1142-1147, 2007.

[9] P. Brochu and Q. Pei, "Advances in dielectric elastomers for actuators and artificial muscles," Macromolecular Rapid Communications, vol. 31, pp. 10-36, 2010.

[10] V. Ranjan, L. Yu, M. B. Nardelli, and J. Bernholc, "Phase equilibria in high energy density PVDF-based polymers," Physical Review Letters, vol. 99, p. 047801, 2007.

[11] M. Kollosche, H. Stoyanov, S. Laflamme, and G. Kofod, "Strongly enhanced sensitivity in elastic capacitive strain sensors," J. Mater. Chem., vol. 21, pp. 8292-8294, 2010.

[12] T.-I. Yang and P. Kofinas, "Dielectric properties of polymer nanoparticle composites," Polymer, vol. 48, pp. 791-798, 2007.

[13] O. A. Al-Hartomy, F. Al-Solamy, A. Al-Ghamdi, N. Dishovsky, M. Ivanov, M. Mihaylov et al., "Influence of carbon black structure and specific surface area on the mechanical and dielectric properties of filled rubber composites," International Journal of Polymer Science, vol. 2011, pp. 1-8, 2011.

[14] M. B. Heaney, "Measurement and interpretation of nonuniversal critical exponents in disordered conductor-insulator composites," Physical Review B, vol. 52, pp. 12477, 1995.

[15] A. I. Medalia, "Electrical conduction in carbon black composites," Rubber Chemistry and Technology, vol. 59, pp. 432-454, 1986.

[16] Z. Elimat, "AC electrical conductivity of poly (methyl methacrylate)/carbon black composite," Journal of Physics D: Applied Physics, vol. 39, p. 2824, 2006.

[17] Z. Rubin, S. Sunshine, M. Heaney, I. Bloom, and I. Balberg, "Critical behavior of the electrical transport properties in a tunneling-percolation system," Physical Review B, vol. 59, p. 12196, 1999.

[18] Z. Li, J. Zhang, and S. Chen, "Effect of carbon blacks with various structures on electrical properties of filled ethylene-propylene-diene rubber," Journal of Electrostatics, vol. 67, pp. 73-75, 2009.

[19] K. Sau, T. Chaki, and D. Khastgir, "Conductive rubber composites from different blends of ethylene-propylene-diene rubber and nitrile rubber," Journal of Materials Science, vol. 32, pp. 5717-5724, 1997.

[20] M. E. Achour, C. Brosseau, and F. Carmona, "Dielectric relaxation in carbon black-epoxy composite materials," Journal of Applied Physics, vol. 103, pp. 094103, 2008.

[21] M. El Hasnaoui, A. Triki, M. E. Achour, and M. Arous, "Modelling of dielectric relaxation processes of epoxy-resin filled with carbon black particles," Physica B: Condensed Matter, vol. 433, pp. 62-66, 2014.

[22] M. El Hasnaoui, J. Belattar, M. Achour, L. Costa, and F. Lahjomri, "Electrical transport properties of CB/epoxy polymer composites," Optoelectron Adv Mater-Rapid Commun, vol. 6, pp. 610-613, 2012.

[23] Z.-F. Zhang, X.-F. Bai, J.-W. Zha, W.-K. Li, and Z.-M. Dang, "Preparation and dielectric properties of $\mathrm{BaTiO}_{3} /$ epoxy nanocomposites for embedded capacitor application," Composites Science and Technology, vol. 97, pp. 100-105, 2014.

[24] A. Patsidis, K. Kalaitzidou, and G. Psarras, "Dielectric response, functionality and energy storage in epoxy nanocomposites: Barium titanate vs exfoliated graphite nanoplatelets," Materials Chemistry and Physics, vol. 135, pp. 798-805, 2012.

[25] S. Singha and M. J. Thomas, "Dielectric properties of epoxy nanocomposites," IEEE Trans. on Dielectrics and Electrical Insulation, vol. 15, pp. 12-23, 2008.

[26] Y. Bai, Z.-Y. Cheng, V. Bharti, H. S. Xu, and Q. M. Zhang, "High-dielectric-constant ceramic-powder polymer composites," Applied Physics Letters, vol. 76, pp. 3804-3806, 2000.

[27] D.-H. Kuo, C.-C. Chang, T.-Y. Su, W.-K. Wang, and B.-Y. Lin, "Dielectric behaviours of multi-doped BaTiO3/epoxy composites," 
Journal of the European Ceramic Society, vol. 21, pp. 1171-1177, 2001.

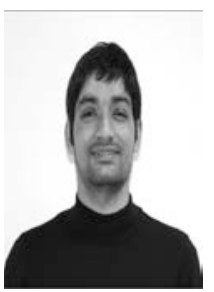

Anup Poudel is a doctoral researcher with the CTRG WIT, Ireland specializing in dielectric thermoplastic elastomerss for energy harvesting and civil infrastructural applications. Anup holds a bachelors degree in biomedical engineering (Purbanchal University, Nepal) and a master of science in innovative technology engineering (Waterford Institute of Technology, Ireland), of which his thesis centered on the development of smart polymer materials technology for cardiovascular applications. Other research interests include electrical impedance spectroscopy and its applications in the biomedical sphere.

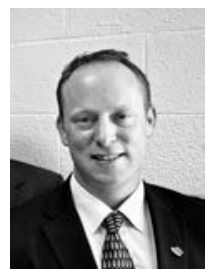

Austin Coffey is a founding member of CTRG and Principal Investigator to a number of the Group's projects. Austin's 18 years' industrial experience spans project management, new product and process development, manufacturing engineering and providing consultation to pharmaceutical, medical device and engineering sectors. He is the current chair of divisions of the Society of Plastics Engineers. Austin's research interests include medical devices, smart water technologies, novel processing of materials, composites (thermoplastic) processing and analysis, supercritical fluid assisted plastics processing, contact lens development and manufacture, controlled drug delivery and materials characterisation.

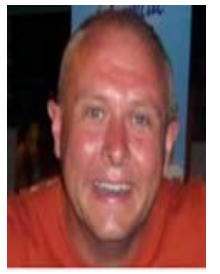

James Kennedy is a lecturer in polymer engineering and also a senior research fellow and director of the Centre for Industrial Solutions and Design in Athlone Institute of Technology Ireland. He holds an MBA and a $\mathrm{PhD}$ in Biomedical Engineering. James has in excess of 80 conference proceedings and over 30 publications in peer reviewed journals, 5 book chapters, 2 patents and a number of invention disclosures.

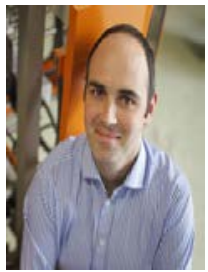

Seans Lyons is the Chair of the European Medical Plastics Division of the Society of Plastics Engineers and is a fellow of Engineers Ireland. Dr. Lyons is the centre manager of the Applied Polymer Technologies research Centre at Athlone Institute of Technology, Ireland. He has worked extensively in product development roles with industry and has published numerous peer reviewed articles on polymer processing in addition to publications in industry magazines such as Medical Plastics

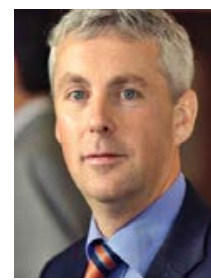

Ken Thomas is head of the School of Engineering at Waterford Institute of Technology, Ireland. Ken completed his $\mathrm{PhD}$ with University College Cork, Ireland on 'The Exploitation of IT in the Irish Architecture-Engineering-Construction Industry' in 2002. He is a member of three research groups at WIT, namely the CTRG, iBERG and BIMC. Ken's research interests include building information modelling (BIM), knowledge management and AEC innovation. He was an Expert Evaluator on the EU Eco-Innovation Initiative from 2010 to 2014. Ken is a co-founder and director if the Construction IT Alliance (CITA) in Ireland.

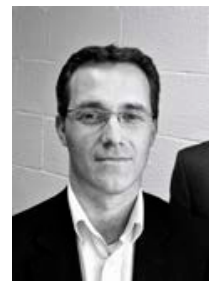

Philip Walsh is a founding member of CTRG and principal investigator. His research interests include experimental physics, solid state physics, semiconductor device engineering, analog, digital and mixed signal integrated circuit design, active medical device design, advanced materials and process for design and manufacture of active biomedical devices. Having worked in these fields for over 15 years, Mr. Walsh has consulted for multiple international semiconductor companies and holds multiple patents and publications in related disciplines. He is a member of the Institute of Physics and a Member of the Institute of Electrical \& Electronic Engineers. 